Int. J. Electrochem. Sci., 16 (2021) Article ID: 210773

International Journal of

ELECTROCHEMICAL

SCIENCE

www.electrochemsci.org

\title{
Polyol synthesis of Ag Nanowires as an electrochemical sensor for the quantification of Carcinogenic Hydrazine
}

\author{
Srinithi Subburaj ${ }^{1}$, Balamurugan Arumugam ${ }^{3}$, Shen-Ming Chen ${ }^{1, *}, T_{s e-W e i}$ Chen $^{1,2}$, \\ Angayarkanni Seetharam ${ }^{3}$, Sayee Kannan Ramaraj, \\ ${ }^{1}$ Electroanalysis and Bioelectrochemistry Lab, Department of Chemical Engineering and \\ Biotechnology, National Taipei University of Technology, No. 1, Section 3, Chung-Hsiao East Road, \\ Taipei 106, Taiwan, ROC. \\ ${ }^{2}$ Research and Development Center for Smart Textile Technology, National Taipei University of \\ Technology, Taipei 106, Taiwan, ROC \\ ${ }^{3}$ PG \& Research Department of Chemistry, Thiagarajar College, Madurai-09, Tamil Nadu, India. \\ *E-mail: smchen78@ms15.hinet.net, sayeekannanramaraj@gmail.com
}

doi: $10.20964 / 2021.07 .74$

Received: 7 April 2021 / Accepted: 19 May 2021 / Published: 31 May 2021

In this work, we have developed Silver nanowires constructed by the sustainable polyol method. The assynthesized nanowires are isolated and characterized with various spectroscopic methods like UVVisible spectrophotometer, X-ray diffraction, and surface morphology analysis through Scanning Electron Microscopy (SEM). The entire analysis has well explained the formation of nanowires proceeded to be an electrocatalytic sensor. To investigate the electrocatalytic activity of as-synthesized silver nanowires, cyclic voltammetry (CV) and Differential Pulse Voltammetry (DPV) systems were utilized. The silver nanowire fabricated over GCE and applied as an electrocatalyst sensor towards the determination of carcinogenic Hydrazine. To investigate the lower concentration ranges and detection limit differential pulse voltammetry method were used. The fabricated sensor gives a very good linear range and the limit of detection for determination of hydrazine was attained to be $0.01-260 \mu \mathrm{M}$ and $0.06 \mu \mathrm{M}$ correspondingly. The as-prepared AgNWs/GCE exposed superior selectivity, storage stability, and reproducibility for the determination of $\mathrm{Hz}$. On affording the above-stated conclusions, we expectantly tested our proposed sensor for real-time monitoring.

Keywords: silver nanowires, polyol method, Carcinogen, Hydrazine, Differential Pulse Voltammetry.

\section{$\underline{\text { FULL TEXT }}$}

(C) 2021 The Authors. Published by ESG (www.electrochemsci.org). This article is an open access article distributed under the terms and conditions of the Creative Commons Attribution license (http://creativecommons.org/licenses/by/4.0/). 